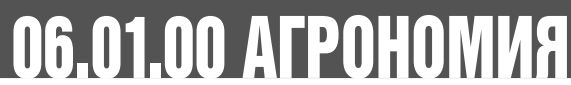

\section{ВЛИЯНИЕ ПРЕПАРАТА МЕГАМИКС НА ПОКАЗАТЕЛИ КАЧЕСТВА ЗЕРНА КОРМОВОГО ЯЧМЕНЯ}

Андреев Николай Николаевич, кандидат сельскохозяйственных наук, доцент кафедры «Биология, химия, технология хранения и переработки продукции растениеводства»

Игнатов Алексей Леонидович, кандидат биологических наук, доцент кафедры «Биология, химия, технология хранения и переработки продукции растениеводства»

Сергатенко Светлана Николаевна, кандидат биологических наук, дочент кафедры «Биология, химия, технология хранения и переработки продукции растениеводства»

ФГБОУ ВО УльянОвский ГАУ

432017, г. Ульяновск, бульвар Новый Венеи, 1; тел.: 8(8422) 55-95-16;

e-mail: andreev919@yandex.ru

Ключевые слова: кормовой ячмень, натура, пленчатость, жидкие минеральные удобрения.

В статье изучали влияние жидкого минерального удобрения "Мегамикс», а также его сочетаний с классическими минеральными удобрениями на показатели качества кормового ячменя. Исследования показали, что самая высокая натура зерна наблюдается в варианте Мегамикс на фоне минеральных серосодержащих удобрений, что выше контроля на 10,6 \% в 2015 году, в 2016 году на 10,3 \%, в 2017 году на 10,3 \%. В среднем за годы исследований прибавка от используемых факторов составила 10,1-10,4 \% в зависимости от варианта. Показатель массы 1000 зерен ячменя в 2015 году был наибольшим в варианте Мегамикс на фоне минеральных удобрений (50,0 2), что выше контроля на 2,6%. В 2016-2017 годах наилучший результат был в варианте совместного использования Мегамикса и серосодержащих минеральных удобрений, выше контроля на 3,4-4,1 \% соответственно. Результаты исследований показывают, что пленчатость зерна ячменя в зависимости от варианта изменяется. Минимальный процент пленчатости наблюдается в 2015 -2016 годах в вариантах Мегамикс в чистом виде и Мегамикс на фоне серосодержащих минеральных удобрений, что составляет 10,3-10,4 \%. В 2017 году показатель пленчатости был выше, что можно объяснить большим количеством осадков в период вегетации.

\section{Введение}

В настоящее время одним из важных компонентов современных технологий производства продукции растениеводства является применение микроэлементов. В малых и сверхмалых концентрациях они стимулируют рост и развитие растений, способствуют увеличению их урожайности и повышению качества продукции. В настоящее время получено и изучено несколько сотен соединений химического и биологического происхождения, обладающих подобным действием на растения [1, 2, 3, 4, 5].

Изучение механизмов действия таких препаратов важно не только для понимания их роли в осуществлении регуляции физиологиче- ских процессов в растительном организме на протяжении всего онтогенеза, но и, главное, с точки зрения их практического использования в растениеводстве.

Для получения высоких урожаев выращиваемая культура должна обеспечиваться не только легкодоступными соединениями азота, фосфора, калия, но и микроэлементами, способствующими эффективному использованию минеральных удобрений, активизирующими процесс роста и развития с/х культур. Микроэлементы необходимы для роста и развития растений на протяжении всего периода вегетации. Но есть критические фазы роста, когда некоторые элементы могут сыграть большую роль в полу- 
чении высоких урожаев и повышении качества. С подъемом урожайности и увеличением выноса питательных веществ растениями из почвы вырастает роль микроэлементов в системе удобрений. Недостаток микроэлементов приводит не только к снижению урожая, вызывает ряд болезней у растений, а иногда и их гибель, но и снижает качество конечной продукции.

Известно, что у некоторых зерновых культур высокое качество продукции трудно сочетается с урожайностью. Тем не менее есть много методов и приемов, соблюдая которые можно добиться увеличения урожайности без ухудшения качества продукции. Одним из таких способов является использование жидких минеральных комплексов $[6,7,8,9,10]$.

Целью исследований являлось изучение влияния жидкого минерального удобрения «Мегамикс», а также его сочетаний с классическими минеральными удобрениями на показатели качества кормового ячменя.

\section{Объекты и методы исследований}

Исследования проводились в 2015-2017 годах на опытном поле Ульяновского ГАУ. Опытная культура - ячмень сорта Нутанс 553. Пло-

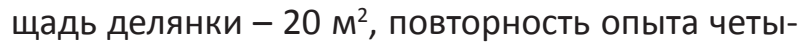
рехкратная, расположение делянок рендомизированное. Объектами исследований являлись: жидкое минеральное удобрение «Мегамикс», а также комплексные минеральные удобрения диаммофоска N15P15K15, диаммофоска N15P15K15S10. B опыте применялась предпосевная обработка семян и, в начале фазы кущения, проводилась фоновая обработка посевов исследуемыми препаратами в концентрациях, рекомендованных производителем. Внесение их осуществлялось одновременно с внесением гербицидов из расчетов 200 л рабочего раствора на 1 га. В опыте присутствовали два фона плодородия: 1-й фон - естественное плодородие, 2-й фон - минеральные удобрения.

Мегамикс - это жидкое минеральное удобрение для внекорневой подкормки с богатым содержанием микроэлементов (г\л): B - 1,7; Cu -7,0; Zn-14; Mn - 3,5; Fe-3,0; Mo-4,6; Co-1,0; $\mathrm{Cr}-0,3$ и макроэлементов (г\л): N - 6; S - 29; Mg -15. Широкий и богатый состав удобрения нацелен на комплексную стимуляцию всех процессов в растении. Также учитывается синергизм и антагонизм отдельных элементов питания. Назначение "МЕГАМИКС»: устранение нехватки микроэлементов; профилактика и лечение эндемических заболеваний; стимулирование корневого питания, активизации ферментов и восполнения недостающих элементов питания; повышение урожайности, благодаря стимуляции ферментативных процессов и продлению вегетации; повышение качества урожая.

Анализы, учеты и наблюдения в эксперименте проводились в соответствии с общепринятыми методиками и ГОСТами. Полевые и лабораторные опыты сопровождались соответствующими наблюдениями, учетами и анализами: содержание белка в зерне по ГОСт 1084691; масса 1000 семян (ГОСТ 12042-80); натура и пленчатость зерна по ГОСТ 5060-86.

Во все годы исследований предшественником была озимая пшеница. Технология возделывания кормового ячменя основывалась на общепринятых в Ульяновской области агротехнических приемах.

\section{Результаты исследований}

Качество зерна определяется совокупностью действия внутренних факторов - естественных особенностей растений и внешних факторов - состава почвы, климатических условий и совокупности агротехнических мероприятий.

Оценка качества зерна осуществляется с использованием следующих показателей: общие показатели качества - обязательные, определяемые в любой партии зерна всех культур признаки свежести (внешний вид, цвет, запах, вкус), зараженность зерна вредителями, влажность и засоренность; специальные, или целевые, - показатели качества, характеризующие товароведно-технологические (потребительские) свойства зерна. Они определяются в партии зерна отдельных культур, используемых на конкретные цели. В эту группу показателей включают пленчатость и выход чистого зерна (крупяные культуры), стекловидность (пшеница, рис), количество и качество сырой клейковины (пшеница), натурную массу (пшеница, рожь, ячмень, овес), жизнеспособность (ячмень пивоваренный). Дополнительные, определяемые при возникшей необходимости, - показатели химического состава зерна, остаточное количество фумигантов (после обработки от вредителей), остаточное количество пестицидов, содержание микроорганизмов, радиационная загрязненность и т. п.

Натура является наиболее древним количественным показателем свойств зерна, применявшимся в хлебной торговле России уже 200 лет назад. Натура служила предметом ожесточенных споров между специалистами. В то время как одни полностью отрицали ее значение, другие видели в ней важнейший критерий для оценки качества зерна. 
Таблица 1

Натура и масса 1000 зерен ячменя, (2015-2017 гг.)

\begin{tabular}{|c|c|c|c|c|c|c|c|c|}
\hline \multirow{2}{*}{ Вариант } & \multicolumn{4}{|c|}{ Натура ячменя, г/л } & \multicolumn{4}{c|}{ Масса 1000 зерен, г } \\
\cline { 2 - 10 } & $2015 г$. & $2016 г$. & $2017 г$. & Среднее & $2015 г$. & $2016 г$. & 2017 г. & Среднее \\
\hline Контроль & 660 & 685 & 682 & 675,7 & 48,7 & 49,2 & 48,5 & 48,8 \\
\hline Мегамикс & 669 & 693 & 690 & 684,0 & 49,8 & 50,6 & 49,7 & 50,0 \\
\hline Контроль + NPK & 666 & 695 & 692 & 684,3 & 48,9 & 49,8 & 49,8 & 49,5 \\
\hline Мегамикс + NPK & 680 & 687 & 698 & 688,3 & 50,0 & 49,6 & 50,2 & 49,9 \\
\hline Контроль + NPKS & 698 & 700 & 695 & 697,7 & 49,7 & 50,7 & 50,0 & 50,1 \\
\hline $\begin{array}{c}\text { Мегамикс + } \\
\text { NPKS }\end{array}$ & 700 & 705 & 701 & 702 & 49,7 & 50,9 & 50,5 & 50,4 \\
\hline $\begin{array}{c}\text { НСР } \\
05\end{array}$ & 4,2 & 1,9 & 3,7 & & 0,19 & 0,33 & 0,85 & \\
\hline
\end{tabular}

Только в результате очень тщательного изучения всех факторов, влияющих на абсолютное значение натуры, удалось установить правильную точку зрения на эту величину и отвести ей должное место в системе качественной оценки зерна. Натура, или объемная масса зерна, включается по существующему Государственному стандарту (ГОСТ Р 53900-2010) в число обязательных показателей при оценке кормового ячменя.

Исследования показали, что самая высокая натура зерна наблюдается в варианте Мегамикс на фоне минеральных серосодержащих удобрений, что выше контроля на 10,6 \% в 2015 году, в 2016 году на 10,3 \%, в 2017 году на 10,3 \%. В среднем за годы исследований прибавка от используемых факторов составила 10,1-10,4 \%, в зависимости от варианта (табл. 1).

Ввиду того, что натура не может дать всестороннего представления о физической добротности исследуемого зерна, в лабораторной практике определяют еще вес 1000 зерен. Этот показатель рассматривается как дополнительный к объемному весу. Масса 1000 зёрен показывает количество вещества, содержащегося в зерне, его крупность. Естественно, что более крупное зерно имеет и более высокую массу 1000 зёрен. В крупном зерне количество оболочек и масса зародыша по отношению к ядру наименьшие. Масса 1000 зёрен является также хорошим показателем качества семенного материала. Крупные семена дают более мощные и более продуктивные растения.

Химический состав зерна зависит от соотношения углеводов и белков в эндосперме. Кроме того, большое влияние на суммарный химический состав оказывает соотношение зародыша и эндосперма, что определяется главным образом степенью выполненности зерна при его наливе.
Показатель массы 1000 зерен ячменя в 2015 году был наибольшим в варианте Мегамикс на фоне минеральных удобрений (50,0 г), что выше контроля на 2,6 \%. В 2016-2017 годах наилучший результат был в варианте совместного использования Мегамикса и серосодержащих минеральных удобрений, выше контроля на 3,4-4,1 \% соответственно (таблица 1).

Пленчатость зерна - это отношение количества оболочек к общему количеству необрушенного зерна, выраженное в процентах.

Пленчатость влияет на пищевую ценность зерна: чем она выше, тем меньше в нем питательных веществ. Кроме того, она создает дополнительные трудности при переработке зерна, а также повышает стоимость готового продукта. По пленчатости различают тонкопленчатые ячмени с содержанием 6-7 \% пленок, средние 8-9 \% пленок и грубопленчатые с содержанием $10 \%$ пленок и более. Пленчатость у зерна зависит от ряда факторов: сортовых особенностей, климатических условий, района выращивания. Пленчатость является одним из показателей пивоваренных качеств ячменя, но и для кормовых ячменей этот показатель играет немаловажную роль, так как именно оболочки богаты минералами и витаминами, что сказывается на кормовой ценности комбикормов, производимых из кормовых ячменей.

Результаты исследований показывают, что пленчатость зерна ячменя изменяется в зависимости от варианта. Минимальный процент пленчатости наблюдается в 2015-2016 годах в вариантах Мегамикс в чистом виде и Мегамикс на фоне серосодержащих минеральных удобрений, что составляет 10,3-10,4 \% (таблица 2). В 2017 году показатель пленчатости был выше, что можно объяснить большим количеством осадков в период вегетации. 
Таблица 2

Влияние препарата Мегамикс на пленчатость ячменя, \% (2015-2017 гг.)

\begin{tabular}{|l|c|c|c|c|}
\hline \multicolumn{1}{|c|}{ Вариант } & 2015 г. 2016 г. 2017 г. & Среднее \\
\hline Контроль & 11,2 & 11,4 & 11,7 & 11,4 \\
\hline Мегамикс & 10,3 & 10,4 & 11,0 & 10,6 \\
\hline Контроль + NPK & 10,6 & 10,9 & 11,5 & 11,0 \\
\hline Мегамикс + NPK & 11,0 & 11,2 & 11,2 & 11,1 \\
\hline Контроль + NPKS & 10,6 & 10,6 & 11,3 & 10,8 \\
\hline Мегамикс + NPKS & 10,3 & 10,3 & 11,1 & 10,6 \\
\hline $\begin{array}{l}\text { НСР } \\
05\end{array}$ & 0,17 & 0,15 & 0,14 & \\
\hline
\end{tabular}

\section{Выводы}

Установлено, что условия дополнительного минерального питания микроэлементами при предпосевной обработке семян и внекорневых подкормках оказывают благоприятное влияние на скорость и направление ферментативных процессов, участвующих в создании качественных показателей в растениях кормового ячменя, в связи с этим можно изменять в желаемом направлении обмен веществ растений.

Таким образом, использование в технологии возделывания кормового ячменя жидкого минерального удобрения "Мегамикс» способствовало повышению качества зерна опытной культуры. Изучаемые факторы обеспечивали более высокий уровень минерального питания растений в течение всего вегетационного периода культуры, что и явилось основой более полного использования генетического потенциала продуктивности растений. Внекорневая обработка вегетирующих растений ячменя опытным препаратом улучшает технологические показатели зерна - натуру зерна, массу 1000 зерен, пленчатость зерна.

\section{Библиографический список}

1. Исайчев, В.А. Урожайность и качество зерна яровой пшеницы в зависимости от предпосевной обработки семян регуляторами роста / В.А. Исайчев, Н.Н. Андреев, А.В. Каспировский // Вестник Ульяновской государственной сельскохозяйственной академии . - 2013. - №3 (23). - С. 14-19.

2. The formation of crop yield grain quality in winter wheat in dependens to application of mineral fertilizers and growth regulators / V.A. Isaychev, N.N. Andreev, V.G. Polovinkin, S.V. Antonova // Research Journal of Pharmaceutical, Biological and Chemical Sciences. 2017. T.8. №2. P. 1974-1983.

3. Кудашкин, М.И. Средства защиты растений, макро- и микроудобрения в технологии возделывания озимой пшеницы интенсивного типа в системе ландшафтного земледелия / М.И. Кудашкин, Ш.И. Ахметов, А.В. Павлинов // Вестник Алтайского государственного аграрного университета. - №9 (71). -2010. - С. 5-8.

4. Кузнецова Наталия Анатольевна. Продукционные и физиолого-биохимические процессы яровой пшеницы в связи с качеством урожая при некорневой обработке микроудобрением ЖУСС-2: дисс. к. б. н.: 03.01.05 / Н.А. Кузнецова.- Москва, 2010. - 221 с.

5. Мельник, А.Ф. Формирование урожайности и качества зерна озимой пшеницы / А.Ф. Мельник, А.Ф. Мартынов // Вестник Орел ГАУ. 2012. - №2. - С. 10-13.

6. Зеленский, Н.А. Влияние элементов технологии выращивания на урожайность и качество зерна сортов озимой пшеницы / Н.А. Зеленский, М.И. Текиева // Научный журнал КубГАУ - Scientific Journal of KubSAU. - 2012. - №78. - C. 675-685.

7. Чурзин, В.Н. Роль регуляторов роста растений и сортов в повышении урожайности и качества зерна озимой пшеницы на светло-каштановых почвах Волгоградской области / В.Н. Чурзин, Ф.А. Серебряков, В.Ф. Серебряков // Известия НВ АУК. - 2013. - №1-1 (29). - С. 83-86.

8. Мельников, Андрей Валерьевич. Формирование урожая и технологических свойств зерна современных сортов и новых генотипов озимой мягкой пшеницы, в зависимости от уровня азотного питания в условиях Центрального района Нечернозёмной зоны: дисс. канд. с.-х. н. 05.18.01; 06.01.01 / А.В. Мельников.- Москва, 2012.-190 с.

9. Сорока, Т.А. Влияние регуляторов роста и микроэлементов на урожайность и качество зерна озимой пшеницы / Т.А. Сорока // Известия ОГАУ. - 2012. - №1-1. - С. 42-44.

10. Титков, В.И. Урожай и качество зерна яровой мягкой пшеницы в зависимости от обработки семян микроэлементами / В.И. Титков, В.В. Безуглов, В.М. Лыскин // Известия ОГАУ. - 2009. - №22-2. - С. 21-23. 


\title{
INFLUENCE OF MEGAMIX COMPOUND ON THE GRAIN QUALITY PARAMETRES OF FEED BARLEY
}

\author{
Andreev N.N., Ignatov A.L., Sergatenko S.N. \\ FSBEI HE Ulyanovsk SAU \\ 432017, Russia, Ulyanovsk, Noviy Venets bld., 1 .; tel .: 8 (8422) 55-95-16; \\ e-mail: andreev919@yandex.ru
}

Key words: feed barley, nature, filminess, liquid mineral fertilizers.

The aim of the research was to study the effect of the liquid mineral fertilizer Megamix, as well as its combinations with classical mineral fertilizers, on the quality parametres of feed barley. Studies have shown that the highest grain nature is observed in the variant of Megamix used in combination with mineral sulfur-containing fertilizers, which is $10.6 \%$ higher than in $2015,10.3 \%$ in 2016 , and $10.3 \%$ in 2017 , compared with control variant. On average, over the years of research, the increase from the factors used was 10.1-10.4\%, depending on the variant. The mass index of 1000 barley grains in 2015 was the largest in the variant of Megamix used together with mineral fertilizers (50.0 g), which was 2.6\% higher than the control. In 2016-2017, the best result was obtained in the variant of combined application of Megamix and sulfur-containing mineral fertilizers, it was above the control by 3.4-4.1\%, respectively. The results of the studies show that the filminess of barley grain varies depending on the variant. The minimum percentage of filminess is observed in 2015 -2016 in the variants of Megamix in its pure form and Megamix together with sulfur-containing mineral fertilizers, which was 10.3-10.4\%. In 2017, the film index was higher, which can be explained by the large amount of precipitation during the vegetation period.

Bibliography

1. Isaychev, V.A. Yield and quality of spring wheat grain, depending on pre-sowing seed treatment with growth regulators / V.A. Isaychev, N.N. Andreev, A.V. Kaspirovskiy // Vestnik of Ulyanovsk State Agricultural Academy. - 2013. - №3 (23). - P. 14-19.

2. Isaychev, V.A. The formation of crop yields in winter wheat in dependens to application of mineral fertilizers and growth regulators / V.A. Isaychev, N.N. Andreev, V.G. Polovinkin, S.V. Antonova // Research Journal of Pharmaceutical, Biological and Chemical Sciences. 2017. T.8. No2. P. 1974-1983.

3. Kudashkin, M.I. Means of plant protection, macro- and microfertilizers in cultivation technology of winter wheat of intensive type in the system of landscape agriculture / M.I. Kudashkin, Sh.I. Akhmetov, A.V. Pavlinov // Vestnik of Altai State Agrarian University. - No 9 (71). -2010. - P. 5-8.

4. Kuznetsova, N.A. Productive and physiological-biochemical processes of spring wheat in connection with crop quality in case of foliar treatment with microfertilizer ZhUSS-2: dissertation of Candidate of Biology .: 03.01.05 / Natalia Anatolyevna Kuznetsova; FSBEI HPE "Kazan State Agrarian University". Moscow, 2010. - $221 p$.

5. Melnik, A.F. Yield formation and grain quality of winter wheat / A.F. Melnik, A.F. Martynov //Vestnik of Orel SAU. - 2012. - No2. - P. 10-13.

6. Zelenskiy, N.A. Influence of elements of cultivation technology on grain yield and quality of winter wheat varieties / N.A. Zelenskiy, M.I. Tekieva // Scientific journal of KubSAU - Scientific Journal of KubSAU. - 2012. - №78. - P. 675-685.

7. Churzin, V.N. The role of plant growth regulators and varieties in increasing the yield and quality of winter wheat on light-chestnut soils of the Volgograd Region / V.N. Churzin, F.A. Serebryakov, V.F. Serebryakov // Izvestiya of NV AUC. - 2013. - №1-1 (29). - P. 83-86.

8. Melnikov, Andrey Valeryevich. Crop formation and technological properties of grain of modern varieties and new genotypes of winter soft wheat, depending on the level of nitrogen nutrition in the conditions of the Central Non-Chernozem Zone: dissertation of Candidate of Agriculture: 05.18.01; 06.01.01 / A.V. Melnikov.- Moscow, 2012. -190 p.

9. Soroka, T.A. Influence of growth regulators and microelements on yield and quality of winter wheat grain / T.A. Soroka // Izvestia of OSAU. - 2012. №1-1. - P. 42-44.

10. Titkov, V.I. Harvest and grain quality of spring soft wheat, depending on seed treatment with microelements / V.I. Titkov, V.V. Bezuglov, V.M. Lyskin // Izvestia of OSAU. - 2009. - № 22-2. - P. 21-23. 